QUALITY IMPROVEMENT REPORT

\title{
Hearing half the message? A re-audit of the care of patients with acute asthma by emergency ambulance crews in London
}

\author{
H Snooks, M Halter, Y Palmer, H Booth, F Moore
}

Qual Saf Health Care 2005;14:455-458. doi: 10.1136/qshc.2004.012336

See end of article for authors' affiliations .....................

Correspondence to: Dr H Snooks, Centre for Health Improvement Research and Evaluation, Clinical School, University of Wales Swansea, Swansea SA2 ODD, UK; h.a.snooks@swan.ac.uk

Accepted for publication 17 October 2005

Problem: An initial audit of the care provided to emergency asthma patients by the ambulance service was carried out in 1996. Some under-recognition and under-treatment of severe asthma was found as well as a lack of documentation of patient condition on scene. A re-audit was undertaken in 1999.

Design: A multidisciplinary advisory group was reconvened. The same method was adopted as for the first audit. Patients included were those administered nebulised salbutamol by crews in the catchment areas of four hospitals and those diagnosed with asthma at the Accident \& Emergency (A\&E) departments of those hospitals between January and March 1999.

Setting: London Ambulance Service.

Key measures for improvement: (1) Accuracy of diagnosis and appropriateness of treatment, and (2) adherence to protocol.

Strategies for change: Following the first audit, treatment protocols were widened and brought into line with the British Thoracic Society guidelines for care of acute asthma patients. The results were widely disseminated within the service and training was initiated for all operational staff.

Effects of change: The number of patients included in the re-audit more than doubled (audit 1: $n=252$, audit 2: $n=532$ ). The increase occurred exclusively in those administered nebulised salbutamol by ambulance crews but diagnosed with conditions other than asthma in A\&E (audit 1: $n=15$, audit 2: $\mathrm{n}=161$ ). The proportion of patients diagnosed with asthma in A\&E who were administered nebulised salbutamol by their attending crew rose from $58 \%$ to $75 \%$. However, 43 asthma patients were not treated; several of these were not recognised as suffering from asthma and others fell within the changed protocols for treatment. Adherence to protocol for administration of salbutamol remained high. Pre-hospital documentation of key observations did not improve.

Lessons learnt: Messages from the first audit seem to have been acted upon selectively. Implementing change is complex, and re-audit is necessary to understand the effects of the changes made.

$\mathrm{T}$ he prevalence of asthma continues to rise internationally and, although deaths from acute asthma are relatively rare, ${ }^{2} 3$ studies have consistently identified factors which may contribute to preventable death and severity of illness. Deficiencies in management identified several years agoincluding underestimation of severity of attacks, inadequate assessment, monitoring and treatment of attacks and delays in transportation to hospital ${ }^{4-7}$ - have been shown recently to persist. $^{89}$

During the 1990s UK ambulance personnel were trained to administer nebulised salbutamol to patients with acute asthma according to a treatment protocol. An oxygen driven nebuliser is used for salbutamol administration. Published research evidence supports the efficacy of this pre-hospital intervention, ${ }^{10-12}$ but evidence concerning the quality of care given has been sparse. In this context, the London Ambulance Service (LAS) carried out a clinical audit of the care of asthma sufferers in 1996.

The main findings of this initial audit were that, although overall accuracy of diagnosis was high, undertreatment was of some concern and pre-hospital documentation of observations was poor (box 1). ${ }^{13}$ These findings fitted in with the research background of failure to recognise and adequately treat patients with acute severe asthma. As a result of the audit, ambulance service treatment protocols for the care of acute asthma were revised, based on the audit findings and on newly emerged national guidelines produced by the British Thoracic Society (table 1 ). ${ }^{14}$
The new treatment protocols were distributed individually to all frontline staff and the audit findings were publicised widely throughout the Trust through newsletters and posters at ambulance stations. Members of the audit team presented the findings to trainers who incorporated a 2 hour session on the care of patients with acute asthma in the post-proficiency training that all crews undertook during the following year. The results of the first audit were presented at national conferences and published in an academic journal to increase the dissemination of findings. ${ }^{13}$

\section{OUTLINE OF PROBLEM}

The aim of implementing these findings was to achieve change in practice that would improve the quality of care given to acute asthmatic patients in the pre-hospital environment. The difficulties of achieving change in practice based on audit or research findings are well documented, ${ }^{15} 16$ and a common criticism of audit projects is that all stages of the audit cycle are rarely completed..$^{17}$

This re-audit in 1999 sought to measure the effects of the changes made on patient care.

\section{KEY MEASURES FOR IMPROVEMENT}

The objectives of the re-audit focused on areas of concern from the original audit: (1) to assess the accuracy of diagnosis and the appropriateness of treatment of patients 
Box 1 Key findings from first audit carried out in 1996

Timeliness of response

Response times for 999 calls included in the study ranged from 4 to 25 minutes, with an average of 11.24 minutes. $84.5 \%$ of calls were attended within 14 minutes, falling short of the national standard at the time of $95 \%$ of all 999 calls to be attended within this time. The response times recorded in the study reflected LAS performance at the time of the study. Accuracy of diagnosis and appropriateness of treatment

Patients administered nebulised salbutamol by their attending crew: Of 173 patients in the study catchment area, 110 were diagnosed with asthma in A\&E; 48 had no diagnosis recorded, and 15 were diagnosed with conditions other than asthma. On clinical review these patients were not judged to have suffered any adverse consequences as a result of their care.

Patients diagnosed with asthma in A\&E: Of 189 ambulance transported patients diagnosed with asthma in the A\&E department during the study period, 79 had not been given nebulised salbutamol by their attending crew. Thirty six of these patients did not meet treatment protocols in place at the time for salbutamol administration (full medication already taken; no confirmed history of asthma; too young). 16 patients were not diagnosed as having acute asthma by their attending crew.

\section{Adherence to protocol}

Initial peak flow measurements, pulse rate, and respiratory rate were recorded in $46 \%, 72 \%$ and $52 \%$ of cases, respectively. Second readings were very rare $(4 \%, 0 \%, 0 \%$, respectively).

All patients administered salbutamol received oxygen with the drug through the oxygen driven nebuliser. Of the other patients, 22 received no oxygen at all.

Treatment protocols for administration of salbutamol were adhered to in all but seven cases where the full dosage was given initially instead of in stages. No adverse incidents were judged to have resulted.

\section{Conclusions of first audit}

Undertreatment rather than overtreatment was of concern. This was due to restrictive protocols and under-recognition linked to failure to record pre-hospital observations.

with acute asthma by LAS crews; and (2) to assess adherence to protocol by LAS personnel when administering nebulised salbutamol.

\section{STRATEGIES FOR CHANGE}

An Asthma Audit Advisory Group (AAAG) was reconvened, including frontline ambulance personnel and training staff, Accident and Emergency (A\&E) consultants, an asthma specialist nurse, a lay person, a GP, respiratory physicians, and clinical audit staff.

The methods were as similar as possible to the first audit so that results could be compared and the impact of the changes made assessed. The audit was retrospective with patients included between 1 January and 31 March 1999, the same period of the year as in the first audit.

\section{Patient identification}

Inclusion criteria were identical to the first audit. Ambulance service and A\&E records were retrieved for those who were either (1) administered nebulised salbutamol by attending crew in the catchment area of four participating A\&E departments (one A\&E department that had closed was
Table 1 Treatment protocols for acute asthma, before and after initial audit

\begin{tabular}{|c|c|}
\hline Before 1st audit & After 1st audit \\
\hline $\begin{array}{l}\text { Initial dosage of salbutamol } \\
2.5 \mathrm{mg} \text { for adults and } 1.25 \mathrm{mg} \\
\text { in children between the ages of } \\
1 \text { and } 5 \\
\text { If patient already taken } 5 \mathrm{mg} \\
\text { nebulised salbutamol before } \\
\text { arrival of ambulance, could have } \\
\text { no more }\end{array}$ & $\begin{array}{l}\text { Initial dosage of salbutamol } 5 \mathrm{mg} \\
\text { for adults and children over the age } \\
\text { of } 5 \text {, and } 2.5 \mathrm{mg} \text { for children under } \\
5 \\
\text { Unlimited, based on presenting } \\
\text { clinical symptoms }\end{array}$ \\
\hline $\begin{array}{l}\text { Second dose of } 2.5 \mathrm{mg} \text { for those } \\
\text { over } 5 \text { could be given en route to } \\
\text { hospital if the patient was still in } \\
\text { respiratory distress }\end{array}$ & $\begin{array}{l}\text { Unlimited, based on presenting } \\
\text { clinical symptoms }\end{array}$ \\
\hline $\begin{array}{l}\text { Administration of salbutamol to } \\
\text { patients with a known history of } \\
\text { asthma who present with either } \\
\text { an acute asthma attack or } \\
\text { status asthmaticus }\end{array}$ & $\begin{array}{l}\text { Previous history of asthma was no } \\
\text { longer required. Administration } \\
\text { based on the presence of clinical } \\
\text { signs-audible wheeze, } \\
\text { bronchospasm }\end{array}$ \\
\hline $\begin{array}{l}\text { Pulse rate, respiratory rate, and } \\
\text { peak expiratory flow rate to be } \\
\text { recorded before and after } \\
\text { administration of nebulised } \\
\text { salbutamol }\end{array}$ & No change \\
\hline
\end{tabular}

replaced with a nearby department of a similar size) or (2) diagnosed with asthma in one of the participating A\&E departments following conveyance by emergency ambulance.

Data were gathered for patients included in the audit from a manual check of patient report forms (PRFs) filled out by crews for each patient attended during the study period and from routine electronic A\&E records supplemented with manually retrieved A\&E cards where necessary.

\section{Power of study}

In the first audit, 58\% of ambulance transported patients diagnosed with asthma in A\&E were treated with nebulised salbutamol by their attending crew. In order to have a $90 \%$ chance of detecting an increase in salbutamol administration in this group of $25 \%$ at the $5 \%$ level of significance, the sample size required for the re-audit was 227 .

\section{Analysis of data}

Statistical Package for Social Scientists (SPSS) for Windows was used for quantitative analysis. Descriptive data are presented with comparisons with the first audit where appropriate.

\section{OUTCOMES}

Of the 489 patients administered nebulised salbutamol by their ambulance crew, in 64 cases their A\&E records were missing and in 108 no diagnosis was recorded in A\&E. The number of patients included in the audit more than doubled (audit $\mathrm{l}: \mathrm{n}=252$, audit $2: \mathrm{n}=532$ ), with increased numbers at each hospital as well as in those not conveyed to A\&E.

\section{Objective 1: Accuracy of diagnosis and appropriateness of treatment of acute asthma by ambulance staff}

Patients diagnosed with asthma in A\&E

For those who were diagnosed with asthma in A\&E, the proportion of patients for whom nebulised salbutamol had been administered by their attending crew had risen from $58.2 \%(110 / 189)$ in the first audit to $75.2 \%(131 / 174)$ in the re-audit (95\% CI of difference $16.5 \%$ to $17.5 \%$; table 2 ).

The PRFs of the 43 patients diagnosed with asthma in A\&E but not administered pre-hospital salbutamol were reviewed (table 3). In 25 cases no reason for not administering 
Table 2 Accuracy of diagnosis of asthma compared with first audit

\begin{tabular}{lcclll}
\hline & \multicolumn{2}{l}{$\begin{array}{l}\text { Administered nebulised } \\
\text { salbutamol }\end{array}$} & & \multicolumn{2}{l}{$\begin{array}{l}\text { Not administered nebulised } \\
\text { salbutamol }\end{array}$} \\
\cline { 2 - 3 } & First audit & Re-audit & & First audit & Re-audit \\
\hline Diagnosed with asthma in A\&E & $110(63.6)$ & $131(26.8)$ & & $79(100)$ & $43(100)$ \\
$\begin{array}{l}\text { Diagnosed with condition other } \\
\text { than asthma in A\&E }\end{array}$ & $15(8.7)$ & $161(32.9)$ & & 0 & 0 \\
$\quad$ COPD & $9(5.2)$ & $74(15.1)$ & & 0 & 0 \\
$\begin{array}{l}\text { Other diagnosis } \\
\text { Missing A\&E diagnosis/notes }\end{array}$ & $6(3.5)$ & $87(17.8)$ & & 0 & 0 \\
Not conveyed & $42(24.3)$ & $176(36.0)$ & & 0 & 0 \\
Total & $6(3.5)$ & $21(4.3)$ & & 0 & 0 \\
\hline Values in parentheses are percentages. & $173(100)$ & $489(100)$ & $79(100)$ & $43(100)$ \\
\hline
\end{tabular}

nebulised salbutamol was documented, nine gave a reason that should have been eliminated by the change in treatment protocols, and for seven patients the crew member had recorded that symptoms were mild. Pre-hospital vital signs were not consistently recorded for these patients and 20 were not recorded as having been administered oxygen, although 33 received nebulised bronchodilators in A\&E and a quarter of this group were admitted to hospital from A\&E.

Patients administered nebulised salbutamol by their attending crew

Only 131 patients $(26.8 \%)$ given nebulised salbutamol by their attending crew received a diagnosis of asthma in A\&E, with $32.9 \% \quad(n=161)$ receiving a diagnosis other than asthma, a much higher proportion than the $8.7 \%(\mathrm{n}=15)$ in audit $1\left(\chi^{2} 67.3\right.$, df $\left.1, p=0.000\right)$. Seventeen of the patients with diagnoses other than asthma in the re-audit gave cause for concern due to their condition at A\&E-namely, those who were drowsy on arrival $(n=6)$, admitted to ICU/CCU $(n=9)$, or died $(n=2)$.

\section{Objective 2: Adherence to protocol}

Adherence to protocol for administration of salbutamol was high $(\mathrm{n}=390,81.6 \%$, table 4$)$, although lower than in audit $\mathrm{l}$ $(95.9 \%)$. In most cases of non-compliance the patient was administered a lower initial dosage than now indicated in the protocol. Pre-hospital documentation of key observations showed a mixed picture, but did not improve overall (table 5).

\section{LESSONS LEARNT}

\section{Summary of effects of change}

The proportion of patients diagnosed with asthma in A\&E who were given salbutamol by their attending crew (sensitivity) had risen substantially since the first audit. The number of patients administered nebulised salbutamol

Table 3 Patients diagnosed with asthma but not given nebulised salbutamol by their attending crew: review of pre-hospital documentation and A\&E outcomes

\begin{tabular}{lcc}
\hline Reason documented & Re-audit & First audit \\
\hline No reason given & $14(32.6)$ & $13(16.5)$ \\
Not diagnosed with asthma by crew & $11(25.6)$ & $16(20.3)$ \\
Full medication already taken & $9(20.9)$ & $19(24.0)$ \\
Too young & $0(0)$ & $2(2.5)$ \\
No previous diagnosis of asthma & $0(0)$ & $15(19.0)$ \\
Mild symptoms & $7(16.3)$ & $4(5.0)$ \\
GP on scene & $1(2.3)$ & $9(11.4)$ \\
Crew not trained to administer & $0(0)$ & $1(1.3)$ \\
nebulised salbutamol & $1(2.3)$ & $0(0)$ \\
Patient refused & 43 & $79(100)$ \\
Total & & \\
\hline Values in parentheses are percentages. & &
\end{tabular}

Table 4 Administration of nebulised salbutamol by crews: adherence to protocol

\begin{tabular}{|c|c|c|c|}
\hline $\begin{array}{l}\text { Initial dosage } \\
\text { (mg) }\end{array}$ & $\begin{array}{l}\text { Age } \\
<5 \text { years }\end{array}$ & $\begin{array}{l}\text { Age } \\
\geqslant 5 \text { years }\end{array}$ & Total \\
\hline 2.5 & 14 & 55 & 69 \\
\hline 5.0 & 2 & 376 & 378 \\
\hline 7.5 & - & 13 & 13 \\
\hline 10 & - & 16 & 16 \\
\hline 15 & - & 2 & 2 \\
\hline Total & 16 & 462 & 478 \\
\hline
\end{tabular}

The age of one patient was not recorded and dosage information was missing in a further 10 cases.

Patients whose treatment was outside of protocols are shown in italics.

Table 5 Documentation of key observations in both audits

\begin{tabular}{lll}
\hline & $\begin{array}{l}\text { First audit } \\
\text { (n= 252) }\end{array}$ & $\begin{array}{l}\text { Re-audit } \\
\text { (n=532) }\end{array}$ \\
\hline $\begin{array}{l}\text { Assessment of consciousness } \\
\text { level (AVPU) }\end{array}$ & $203(80.6)$ & $510(95.7)$ \\
$\begin{array}{l}\text { Peak flow* } \\
\text { Respiratory rate }\end{array}$ & $114(48.3)$ & $142(30.2)$ \\
$\begin{array}{l}\text { Pulse rate } \\
\text { Blood pressure }\end{array}$ & $115(45.6)$ & $262(49.3)$ \\
\hline
\end{tabular}

Values in parentheses are percentages.

*Patients for whom it was documented that a peak flow measurement could not be obtained due to distress, refusal, or other reason are

excluded ( 1 st audit $n=16$; re-audit $n=62$ ).

had more than doubled. However, the proportion of these patients diagnosed with asthma in A\&E had fallen significantly, with a very large increase in patients diagnosed with chronic obstructive pulmonary disease (COPD). Adherence to the treatment protocol when salbutamol was given was high in terms of drug dosage levels, although documentation of key patient observations remained low.

\section{Study limitations}

In this study we used the asthma diagnosis in the A\&E as the "gold standard" against which to compare pre-hospital treatment. Although deficiencies in A\&E care meant this was not a perfect measure, this was judged by the AAAG to be the best standard available, and certainly preferable to confining data collection to ambulance service records only. However, the level of missing data from the participating A\&E departments was high in both audits.

The design of this audit as a "before and after" study with no concurrent control means that any changes seen may not be attributable to the changes in protocol and associated 
training. Other factors such as changes in recording practices could account for the differences found. While it is possible that these factors may have affected the audit findings, we have no evidence of any changes during the period of the study that indicate this to be the case.

\section{Implications for the service}

These findings were unanticipated and showed that crews responded to changes in the treatment protocol but were less receptive to other messages. Practice changed between the two audits, with a large increase seen in the numbers of people administered nebulised salbutamol and a reduction in the proportion of cases missed. This represents an improvement in the care of patients with acute asthma who call 999. It did also result in a large increase in the number of patients with COPD being administered nebulised salbutamol, an important treatment for this condition but carrying a small risk of carbon dioxide retention as a result of the high flow oxygen used to drive the nebulisers used in pre-hospital care. Certainly, a small number of patients arrived in A\&E with a reduced level of consciousness, but whether this was a result of the primary problem or its treatment requires further investigation. The view of the clinical advisors to the study was that overtreatment is less of a concern than undertreatment, and a subset of those who should have received salbutamol before arrival at the hospital still did not. Published research, reinforced by the BTS guidelines for the care of acute asthma patients, stresses the need to take and record key observations in order to avoid missing cases of serious asthma. ${ }^{11} 1920$ This message was highlighted in all training, educational, and dissemination materials. It did not appear to be heard, however, with documentation of key observations remaining patchy. This suggests that protocols were applied somewhat indiscriminately, without appropriately linking clinical observations to practice.

Services implementing measures to improve the quality and safety of care provided by ambulance crews should not assume that revision of treatment protocols and provision of additional training will necessarily achieve the improvements sought.

\section{NEXT STEPS}

Concern about overtreatment using the oxygen driven nebuliser has prompted new research in this service. The need for clear documentation is to be re-emphasised and will be monitored through continuous audit based on clinical supervision and performance indicators.

This re-audit demonstrates the complexity of changing practice in this setting and reinforces the need to carry out audit in a continuous cycle as the effects of change can be quite unpredictable.

\section{ACKNOWLEDGEMENTS}

The authors thank the members of the Asthma Audit Advisory Group, participating crews, and the staff of A\&E departments who helped in the retrieval of notes.

\section{Authors' affiliations}

H Snooks, Centre for Health Improvement Research and Evaluation, Clinical School, University of Wales Swansea, UK

M Halter, Y Palmer, F Moore, London Ambulance Service NHS Trust, UK H Booth, UCLH, University College Hospital, UK

The study was funded within the ambulance service.

Competing interests: none.

HS designed and led the project and completed the drafting of the paper. MH undertook analysis and wrote the first draft of the paper. YP undertook data collection, coordinated the study, and contributed to the drafting of the paper. HB acted as clinical advisor to the project and contributed to the drafting of the paper. FM provided clinical guidance to the study and contributed to the drafting of the paper.

Following advice, ethical approval was not formally sought for this audit which did not involve approaching patients.

\section{REFERENCES}

1 Soriano JB, Kiri VA, Maier WC, et al. Increasing prevalence of asthma in UK primary care during 1990s. Int J Tuberc Lung Dis 2003;7:415-21.

2 Wobig EK, Rosen P. Death from asthma: rare but real. J Emerg Med 1996;14:233-40.

3 McFadden ER Jr, Warren EL. Observations on asthma mortality. Ann Intern Med 1997;127:142-7.

4 Model D. Preventable factors and death certification in death due to asthma. Respir Med 1995;89:21-5.

5 British Thoracic Association. Death from asthma in two regions of England. BMJ 1982;285:1251-5.

6 Omerod LP, Stableforth DE. Asthma mortality in Birmingham 1975-7: 53 deaths. BMJ 1980;280:687-90.

7 MacDonald B, Seaton A, Williams DA. Asthma deaths in Cardiff 1963-74: 90 deaths outside hospital. BMJ 1976;i:493-5.

8 Harvey S, Forbes L, Jarvis D, et al. Accident and Emergency departments are still failing to assess asthma severity. Emerg Med J 2003;20:329-31.

9 Pinnock H, Johnson A, Young P, et al. Are doctors still failing to assess and treat asthma attacks? An audit of the management of acute attacks in a health district. Respir Med 1999;93:397-401.

10 Fergusson RJ, Stewart CM, Wathen CG, et al. Effectiveness of nebulised salbutamol administered in ambulance to patients with severe asthma. Thorax 1995;50:81-2.

11 Delbridge T. Prehospital asthma management. Prehosp Emerg Care 2003;7:42-7.

12 Barriot P, Riou B. Prevention of fatal asthma. Chest 1987;92:460-6.

13 Snooks H, Hartley-Sharpe C, Booth H, et al. Audit of care of acute asthma patients by ambulance crews in London. Pre-hosp Immediate Care 1999:3:76-80

14 British Thoracic Society, British Paediatric Association, Research Unit of the Royal College of Physicians of London, et al. Guidelines for the management of acute severe asthma in adults and children. Thorax 1993;48(Suppl 1):S1-24.

15 Johnston G, Crombie IK, Davies HTO, et al. Reviewing audit: barriers and facilitating factors for effective clinical audit. Qual Health Care 2000;9:23-6.

16 Berger A. Why doesn't audit work? BMJ 1998;316:875-6.

17 Gnanalingham J, Gnanalinghan MG, Gnanalingham KK. An audit of audits: are we completing the cycle. J R Soc Med 2001;94:288-9.

18 Ong CC, Chorbachi R. The difficulties encountered in competing an audit cycle in a district general hospital. Int J Clin Pract 1998;52:298-9.

19 Shim CS, Williams MH. Evaluation of the severity of asthma: patients versus physicians. Am J Med 1980;93:11-3.

20 Baumann UA, Haerdi E, Keller R. Relations between clinical signs and lung function in bronchial asthma: how is acute bronchial obstruction reflected in dyspnoea and wheezing? Respiration 1986;50:294-300. 